\title{
Wind Effect on Measured Atmospheric Pressure
}

\author{
HENRY LIU \\ Civil Engineering Department, University of Missouri-Columbia, Columbia, Missouri
}

GRANT L. DARKOW

Atmospheric Science Department, University of Missouri-Columbia, Columbia, Missouri

(Manuscript received 14 September 1987, in final form 3 March 1988)

\begin{abstract}
Wind generated pressure inside buildings, normally referred to as "internal pressure" in engineering literature, has a profound effect on the atmospheric pressure measured with indoor barometers during severe storms. The magnitude of the internal pressure is proportional to the dynamic pressure (stagnation pressure) which in turn increases with the square of the wind speed. Normally, this pressure is negative, and it has a magnitude in the neighborhood of $50 \%$ of the stagnation pressure. Its value changes drastically when an opening such as a door or window is opened or broken in high winds. The internal pressure also fluctuates readily with the fluctuations of the external pressure when a large opening exists. Surface pressure measurements taken in severe storms may contain serious errors if this internal pressure effect is not corrected. The paper summarizes latest research findings on internal pressure reported in the literature, and explores their implications to meteorology-especially to the study of severe storms such as hurricanes and tornadoes. Measures to correct or reduce the error generated by internal pressure are also discussed.
\end{abstract}

\section{Introduction}

Accurate determination of atmospheric pressure from measurements is important for the understanding of meteorological events such as severe storms. However, the pressure recorded by a barometer is often affected by instrument factors (e.g., the sensitivity and the frequency response of sensors) and by weather factors (e.g., wind and temperature), as discussed in standard handbooks such as Brock and Nicolaidis (1984). It is highly desirable to understand how these factors influence barometric measurements so that measurement errors can be either corrected or kept at a minimum.

It has been known for a long time that wind affects barometric readings by generating a dynamic pressure superimposed on the true atmospheric pressure. The dynamic pressure increases with the square of the wind speed. It is also well-known that opening and closing the doors of a building in a wind affects barometric measurements and causes "pumping" in the barographs. What is not known, however, is how to determine the magnitude of this wind effect so that it can be corrected for or minimized in the measurements. For instance, it has long been thought that if doors and windows are closed during wind, or if buildings have

Corresponding author address: Dr. Henry Liu, Department of Civil Engineering, University of Missouri-Columbia, 1047 Engineering Building, Columbia, Missouri 65211. uniform openings on all walls, the indoor pressure will not be seriously affected by the dynamic pressure generated by wind. As will be shown herein, latest research findings have proved that this is not the case. High winds can produce (and almost always produce) serious errors in atmospheric measurements. How to reduce this error to an acceptable level presents a challenge to the meteorological profession, especially to those studying severe storms.

Much progress has been made in recent years in understanding the nature of wind-induced pressure inside buildings and its implications to building safety in high winds (Liu and Saathoff 1981 and 1982; Liu, Rhee and Fartash 1986). This new knowledge in wind engineering can now be applied to meteorology for understanding and estimating the error in atmospheric pressure measurements made indoors during wind storms so that the true atmospheric pressure change of the storm can be correctly recognized. The purpose of this paper is to explain how wind affects the pressure inside buildings and how one can take this internal pressure into account in the interpretation of barographs recorded in wind storms. Methods to correct and minimize the wind-induced error in barometric measurements will also be discussed.

\section{Building pressure in steady wind}

When a steady wind blows against a building, it causes the pressure on the external surface of the build- 
ing to vary in a predictable manner. While the external pressure on the windward wall is positive (i.e., above atmospheric or ambient), the pressures on all other sides, including the two side walls, the leeward wall and the roof, are all negative (i.e., below atmospheric or ambient). A pressure coefficient can be defined as follows:

$$
C_{p}=\frac{p-p_{a}}{\frac{1}{2} \rho V^{2}}
$$

where $C_{p}$ is the pressure coefficient which is a dimensionless pressure; $p_{a}$ is the atmospheric pressure, or ambient pressure if different from atmospheric; $p$ is the pressure at any location on the building; $\rho$ the density of the air outside the building; $V$ the free-stream wind velocity (i.e., the wind speed at the location of the building if the building did not exist); the numerator $p-p_{a}$ the pressure relative to ambient, referred to hereafter simply as the "building pressure"; and the denominator $1 / 2 \rho V^{2}$ the "stagnation pressure" or "dynamic pressure" of the free stream. Note that for lowrise buildings, the reference height normally used for the free-stream velocity $V$ is the mean roof height, whereas for high-rise buildings the reference height for $V$ coincides with the height at which $p$ is measured. Differences in the reference height for $V$ result in different values of pressure coefficients. Since the wind is assumed steady in this section, fluctuations of wind are ignored.

The highest pressure generated by wind is at the stagnation point which exists at a location above the center of the windward wall. Since the building pressure at this location is $p-p_{a}=1 / 2 \rho V^{2}$, the value of $C_{p}$ at the stagnation point is equal to one. Elsewhere on the windward wall, $C_{p}$ is less than one but it remains positive. On the other hand, the values of $C_{p}$ on the leeward wall, side walls and the roof are all negative-with the

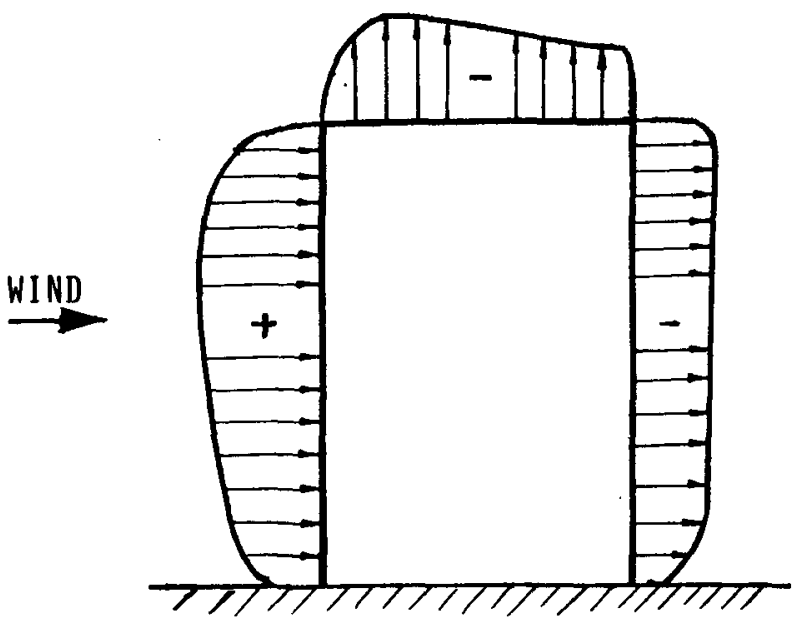

FIG. 1. Wind-generated pressure around a block-type building (external pressure).

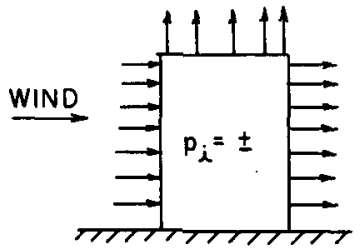

(a) HERMETIC BUILDING

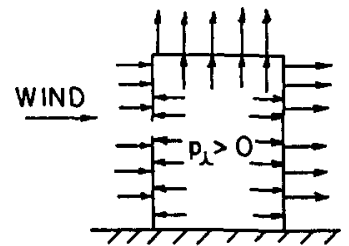

(b) WINDWARD OPENING

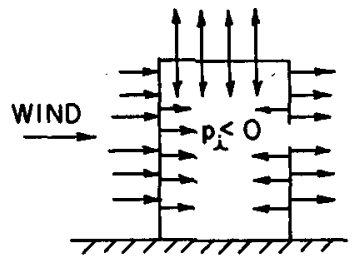

(c) SUCTION OPENING

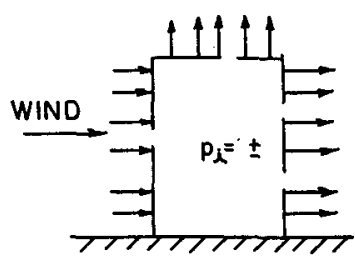

(d) OPENINGS ON MORE THAN ONE SIDE
FIG. 2. Variation of the equilibrium internal pressure with opening. (Note: Wind is from left to right. Arrows show directions of pressure. Arrows outside the building indicate external pressure, whereas arrows inside indicate internal pressure.)

highest negative values encountered near the corners of roofs and walls. Figure 1 illustrates the distribution of $C_{p}$ around a typical block-type building having a flat roof. When the roof is sloped, as for the case of a gabled roof, the negative value of $C_{p}$ for the windward part of the roof reduces. Normally, $C_{p}$ becomes positive on the windward part of a gabled roof when the slope is greater than approximately $30^{\circ}$, but remains negative on the leeward part.

The foregoing discussion refers to the pressure generated on the external surface of buildings-the building external pressure. The building internal pressure behaves quite differently from the building external pressure. While the external pressure varies over the building surface, the internal pressure is uniform inside a building with an open interior, and uniform within each room though different from room to room if the doors between the rooms are tightly shut and if there is only small leakage of air between rooms.

The internal pressure, $p_{i}$, of the building is affected by wind through openings on the building envelope. As shown in Fig. 2, for a building that is perfectly airtight ( such buildings normally do not exist), the building internal pressure is unaffected by the wind or the atmospheric pressure outside. In this case, the internal pressure only depends on, and remains to be, its initial value. However, when a single opening exists on the windward wall as shown in Fig. 2b, the high external pressure that exists near the opening is transmitted into the building, causing the building internal pressure to rise until it reaches the external pressure. This generates a high internal pressure. In Fig. 2c, the opening is on the leeward wall. Since the external pressure is negative 
in this case, the internal pressure must also become negative. The same happens when the opening is on the other suction sides such as the roof or on any side wall. Finally, if openings exist both on the windward and the suction sides, as shown in $2 \mathrm{~d}$, the internal pressure can be either positive or negative, depending on whether the combined area of suction openings is smaller or greater than the combined area of windward openings. If the area of suction openings is sufficiently smaller than the windward openings, then the pressure inside will be positive and vice versa. Note that the condition of $2 \mathrm{~d}$ causes air exchange (natural ventilation) through buildings: the air enters the building through windward openings, and leaves through suction openings. If these openings are large, a strong draft may blow through the building, causing internal damage.

Liu (1975) derived an equation to calculate the steady-state internal pressure of a low-rise building having an open interior and two openings to outside, one on the windward wall and the other on a suction side. The equation is

$$
C_{p_{i}}=\frac{C_{p_{2}}+C_{p_{1}}\left(\frac{A_{1}}{A_{2}}\right)^{2}}{1+\left(\frac{A_{1}}{A_{2}}\right)^{2}}
$$

where $C_{p_{i}}$ is the internal pressure coefficient defined as in Eq. (1) with $p$ changed to $p_{i} ; C_{p_{1}}$ and $C_{p_{2}}$ are respectively the external pressure coefficients for openings 1 and 2-with 1 being the windward openings and 2 the selection opening; $A_{1}$ and $A_{2}$ are respectively the areas of the windward and suction openings. Note that the reference velocity $V$ used in association with Eq. (2) is again the velocity at the mean roof height.

Although Eq. (2) was derived for a building with only two openings, it can be used as an approximation for buildings having any number of openings, including cracks, provided that $A_{1}$ and $A_{2}$ now represent the total opening area on windward wall and suction sides, respectively, and provided that $C_{p_{1}}$ and $C_{p_{2}}$ represent the average values of external pressure coefficients for windward and suction, respectively. Much information exists in the literature (Simiu and Scanlan 1985) on the external pressure coefficients for various types of buildings.

For a block-type building two or three stories high having a flat roof, building standards such as (ANSI 1972) give $C_{p}=+0.8$ for windward, and $C_{p}=-0.6$ for suction sides. Using these approximate values and assuming that the building openings are uniformly distributed around the walls, Eq. 2 yields

$$
C_{p_{i}}=\frac{-0.6+0.8 \times(1 / 3)^{2}}{1+(1 / 3)^{2}}=-0.46
$$

Note that the area ratio of $1 / 3$ comes from the fact that with uniform openings around the walls, there is approximately three times more openings on suction sides (leeward and the two side walls) than on the windward wall. The foregoing calculation shows that with uniform distribution of openings, the internal pressure coefficient is in the neighborhood of -0.5 . In general, the internal pressure of buildings tends to be negative. Roof vents and flues (chimneys) also promote large negative internal pressure. More about the behavior of internal pressure can be found in (Liu and Saathoff 1982).

\section{Unsteady internal pressure}

The foregoing discussion pertains to the internal pressure generated by a steady wind. Since wind is never steady, it is important to know how the internal pressure of buildings departs from the steady-state value which can be predicted from Eq. (2). The transient response of internal pressure following the sudden opening or breakage of a window or door in high winds is also of interest.

Liu and Saathoff (1981) showed that following the breakage or opening of a window or door in high winds, the internal pressure approaches the steady state or equilibrium value in a time $(T)$ approximately given by

$$
T=0.02 \frac{U}{A V}
$$

where $U$ is the internal volume of the building.

For a building of volume $U=500 \mathrm{~m}^{3}$, opening area $A=1 \mathrm{~m}^{2}$, and wind speed $V=20 \mathrm{~m} \mathrm{~s}^{-1}$, Eq. (3) yields $T=0.5 \mathrm{sec}$. This means that when a door or window is suddenly opened, normally it takes less than one second for the internal pressure to reach the equilibrium value. The result also implies that when a window or door is open during high winds, or when the building envelope has much leakage, the internal pressure will fluctuate with the external pressure fluctuations even when the gust frequency is somewhat higher than 1 $\mathrm{Hz}$, unless the window is unusually small, or the building volume is unusually large. When all the windows and doors of a building are closed in a high wind, there will still be leakage of air through walls, cracks and roof vents. Now, the leakage area for a building of a volume of $500 \mathrm{~m}^{3}$ may only be of the order of $0.05 \mathrm{~m}^{2}$. The time to reach equilibrium for this case, with windows and doors closed, is of the order of $10 \mathrm{sec}$.

The foregoing calculation gives a feel as to how quickly the internal pressure can adjust to the change of the external pressure under different opening conditions. It shows that even with all the doors and windows closed and not broken in high winds, there is normally still sufficient air leakages through roof vents and door and window cracks so that the building internal pressure can adjust to the external change in a matter of seconds. Since the gust speed normally refers to a 2 to $3 \mathrm{~s}$ averaging time, this means under ordinary 
conditions Eq. (2) can be used in association with the gust speed at roof height.

\section{Effect on atmospheric pressure measurements}

Accurate measurement of the atmospheric pressure at or near ground level (the surface pressure measurements) is essential to a number of applications, as in the study of the characteristics of severe storms. Such measurements are normally made with barometers or pressure transducers placed inside a building or shelter. During high winds, the barographs obtained in such a manner measure the sum of the ambient and internal pressures-a quantity quite different from the undisturbed atmospheric surface pressure. This wind effect, if not corrected or properly taken into account, can yield erroneous values of the atmospheric pressure outside.

For a typical two-story building with uniform wall openings and some roof vents, the internal pressure coefficient is approximately -0.5 . The error in the atmospheric pressure measurements made indoors in this case can be estimated from Eq. (1). The results are listed in Table 1. For reasons justified in the previous section, the gust speed at roof height should be used in Table 1. Based on the values in Table 1 , a gust speed of $41 \mathrm{mph}\left(18 \mathrm{~m} \mathrm{~s}^{-1}\right)$ can cause an error of $1 \mathrm{mb}$, and a gust speed of $130 \mathrm{mph}\left(58 \mathrm{~m} \mathrm{~s}^{-1}\right)$ can cause an error of $10 \mathrm{mb}$. The error increases rapidly with increasing wind speed because the internal pressure is proportional to the square of velocity. As will be shown in a later example, an error much greater than $1 \mathrm{mb}$ can have serious consequences in the study or understanding of severe storms. This means that all of the surface pressure measurements made in severe wind storms such as hurricanes and tornadoes may contain large errors. Normally, this error tends to make barometric readings lower than they should be. Occasionally, however, if a window or door facing a wind is broken or forced open by the wind, the error caused by internal pressure is positive, making barometric readings higher than they should be. How much error is involved in each case

TABLE 1. Errors in atmospheric pressure measurements made indoors. (Assume $C_{p_{i}}=-0.5$ and $\rho=1.2 \mathrm{~kg} \mathrm{~m}^{-3}$ )

\begin{tabular}{rcccccc}
\hline \hline \multicolumn{3}{c}{ Wind speed } & & & \multicolumn{2}{c}{ Error due to internal pressure } \\
\cline { 1 - 2 } \cline { 6 - 7 }$(\mathrm{mph})$ & $\left(\mathrm{m} \mathrm{s}^{-1}\right)$ & (knots) & & (Pascals) & (mb) & (in. Hg) \\
\hline 25 & 11.2 & 21.7 & & -37.6 & -0.38 & -0.011 \\
50 & 22.4 & 43.5 & & -151 & -1.51 & -0.045 \\
75 & 33.5 & 65.2 & & -337 & -3.37 & -0.100 \\
100 & 44.7 & 87.0 & & -599 & -5.99 & -0.177 \\
125 & 55.9 & 109 & & -937 & -9.37 & -0.277 \\
150 & 67.1 & 130 & & $-1,351$ & -13.5 & -0.399 \\
175 & 78.2 & 152 & & $-1,835$ & -18.4 & -0.542 \\
200 & 89.4 & 174 & & $-2,398$ & -24.0 & -0.709 \\
250 & 112 & 217 & & $-3,763$ & -37.6 & -1.112 \\
300 & 134 & 261 & $-5,403$ & -54.0 & -1.597 \\
\hline
\end{tabular}

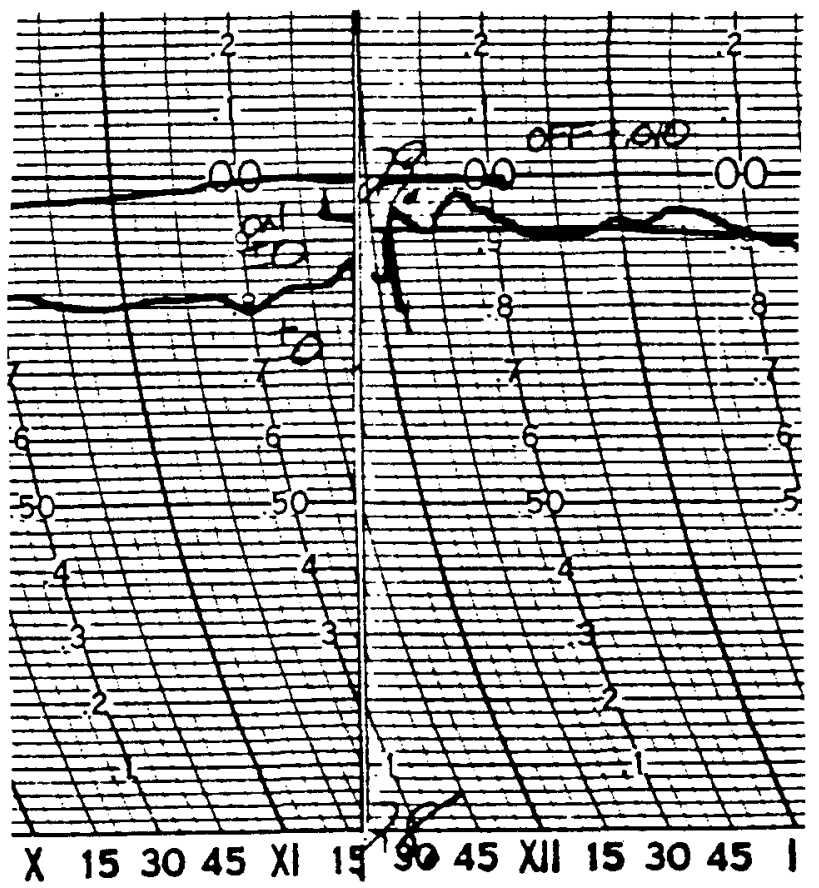

FIG. 3. Barograph of the storm at Regional Airport, Columbia, Missouri, 16 June 1987.

can be determined from Eq. (2) if the wind speed, $V$, and the ratio of windward to suction openings, $A_{1} / A_{2}$, are known.

Figure 3 is an example of a microbarograph recorded by the National Weather Service's station at the Regional Airport, Columbia, Missouri, on the night of 16 June 1985 , when the station was hit by a severe storm with maximum gusts measured at $96 \mathrm{mph}$ ( 83 knots) at the anemometer height of $10 \mathrm{~m}$ above ground. The wind speed record is shown in Fig. 4. The high wind caused severe damage to 24 parked aircraft (mostly single-engine planes tied to the ground by ropes), a hangar and many automobiles. Although no signature echoes, such as a hook echo frequently associated with tornado formation, were detected on the local radar and no visual sightings of a tornado were made, the storm was officially classified as a tornado based on the characteristics of the microbarograph in Fig. 3, and on some other apparent evidence. The sudden drop of the pressure at or near the peak of the storm happened within 5 minutes after midnight and was believed to be characteristic of the drop of pressure that exists at the center of a tornado. This could not have happened in a downburst, since the pressure at the center of a downburst would rise rather than drop.

However, a detailed postdisaster investigation of the storm conducted by Liu and Nateghi (1986) revealed that the wind-speed distribution of the storm, as given in Fig. 5, satisfies the six criteria in Table 2 established by Fujita (1985) for microbursts. The change of wind direction with time, as plotted in Fig. 6, fits approxi- 


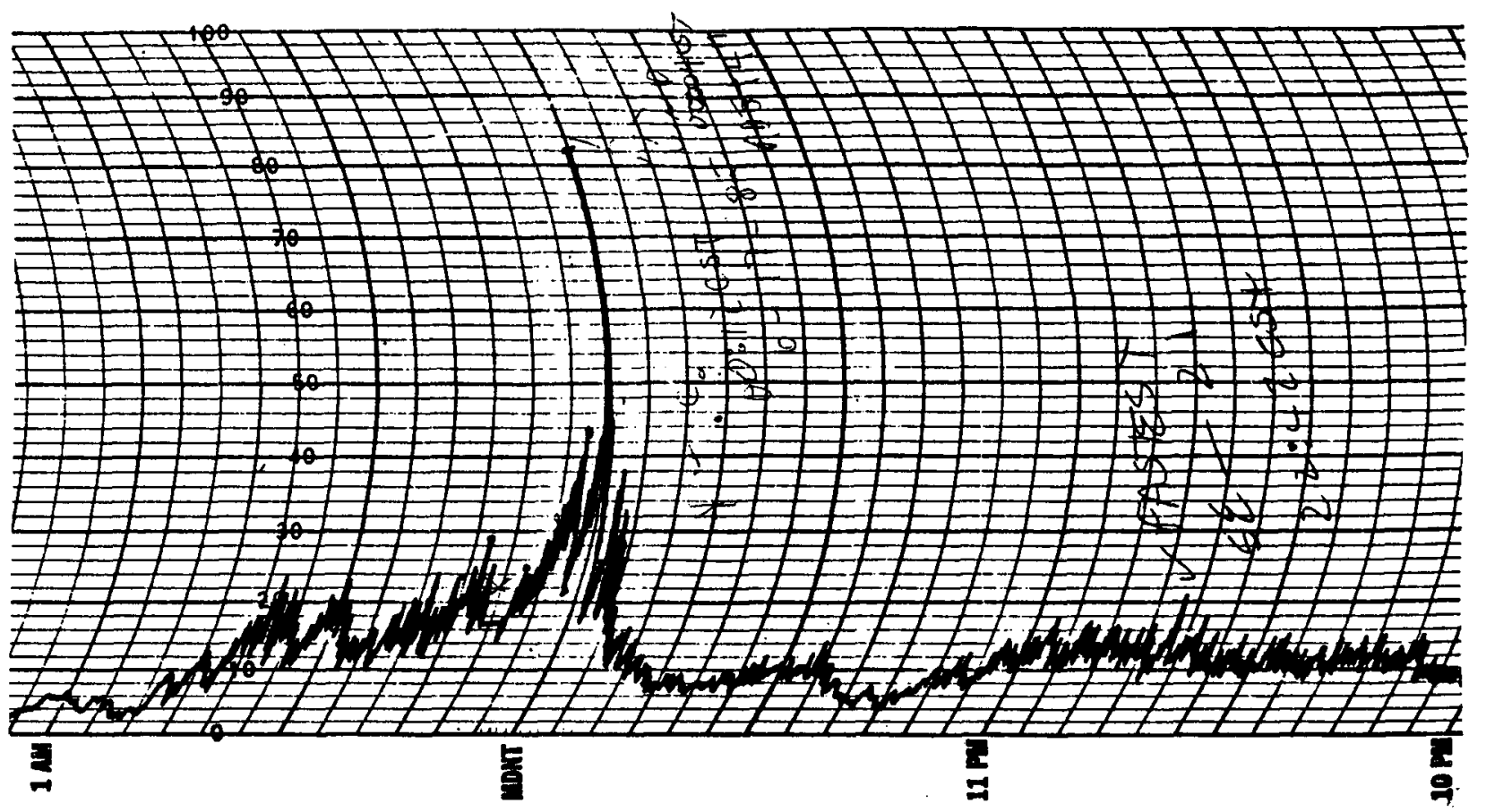

FIG. 4. Wind speed record of the storm. (Note: Chart time was 4 minutes behind CST at midnight.)

mately that of a traveling microburst passing northwest of the anemometer, heading towards the northeast. Moreover, the damage pattern was found to resemble closely that caused by a westerly or southwesterly wind, which happened during the peak of the wind storm. All these suggest that the storm might have been a downburst rather than a tornado. But, why then the sudden drop of pressure in Fig. 3?

The anomaly of the pressure drop can be explained only by the error caused by internal pressure. Because the building had doors and windows on all sides, because all of the windows and doors connected to the instrument room where the barometer was housed were closed and remained intact during the storm, ${ }^{1}$ and because there was a roof vent above the instrument room, the internal pressure coefficient $C_{p_{i}}$ based on gust speed at roof height for this two-story building was estimated to be in the neighborhood of -0.5 . Using Table 1 , the internal pressure drop corresponding to a gust speed of $96 \mathrm{mph}$ is $5.5 \mathrm{mb}$ which is equivalent to 0.16 inch of mercury. An examination of the microbarograph given in Fig. 3 shows that the pressure dropped from 28.88 inches at 2355 CST ( 5 minutes before midnight) to 28.76 inches at 0004 CST ( 4 minutes after midnight). This is a drop of 0.12 inch of mercury which corresponds approximately to the expected change of internal pressure calculated here.

\footnotetext{
'Some exterior doors of the building were broken at the height of the storm, but these doors were not connected to the instrument room.
}

An attempt was made to correct the barograph errors caused by the wind-generated internal pressure during the storm. Owing to poor resolution of the barograph in Fig. 3, two experienced meteorologists familiar with the barograph system were asked to read the pressure from the graph for each minute over a 20 -min period of the storm. The average readings by the two were plotted as the dotted line in Fig. 7; the corresponding wind speed is given as the solid line. Figure 7 reveals a good correlation between the wind speed variation and the pressure variation: generally, as the wind speed

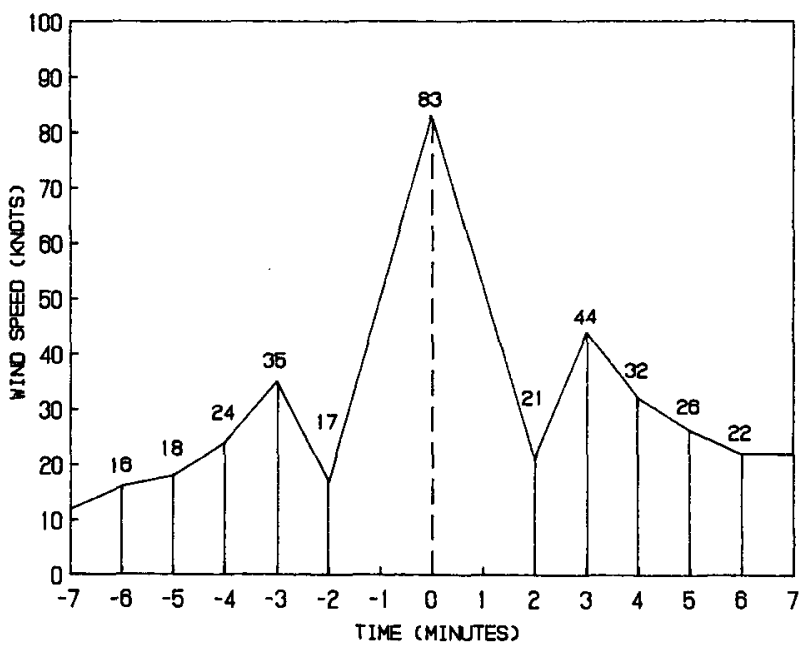

FIG. 5. Wind speed distribution of the storm. 
TABLE 2. Necessary Conditions for Microbursts (Fujita, 1985)

\begin{tabular}{|c|c|}
\hline Condition 1 & Center wind should be faster than $10 \mathrm{~m} / \mathrm{sec}$ \\
\hline Condition 2 & $\begin{array}{l}\text { Center wind should be at least } 5 \mathrm{~m} / \mathrm{sec} \text { faster } \\
\text { than } W+^{\mathrm{a}}\end{array}$ \\
\hline Condition 3 & $\begin{array}{l}\text { Center wind should be at least } 5 \mathrm{~m} / \mathrm{sec} \text { faster } \\
\text { than } W-\end{array}$ \\
\hline Condition 4 & Center wind should be $1.25 \mathrm{~W}+$ or faster \\
\hline Condition 5 & Center wind should be $1.25 \mathrm{~W}-$ or faster \\
\hline Condition 6 & $W+$ should not exceed $1.5 W-$ \\
\hline
\end{tabular}

an the conditions, $W-=\left(W_{-2}+W_{-3} \cdots+W_{-7}\right) / 6$, and $W+$ $=\left(W_{+2}+W_{+3} \cdots+W_{+7}\right) / 6$. Note that $W_{-2}$ is the wind speed at two minutes prior to the peak, and $W_{+2}$ is the wind speed at two minutes after the peak, etc.

increases, the barometric pressure falls and vice versa. The wind speed record in Fig. 7 was then used to calculate the internal pressure variation for each minute, assuming that $C_{p_{i}}=-0.5$ and $\rho=1.2 \mathrm{~kg} \mathrm{~m}^{-3}$. Subtracting this internal pressure from the average barometric readings gives the barograph corrected for internal pressure as the dotted line in Fig. 8. Examination of the graph shows that as the storm approached its peak, the atmospheric pressure rose instead of dropped, as would be expected for a traveling downburst. The foregoing example shows that the error caused by internal pressure, if not recognized and corrected, can lead to serious misrepresentation of the characteristics of severe storms.

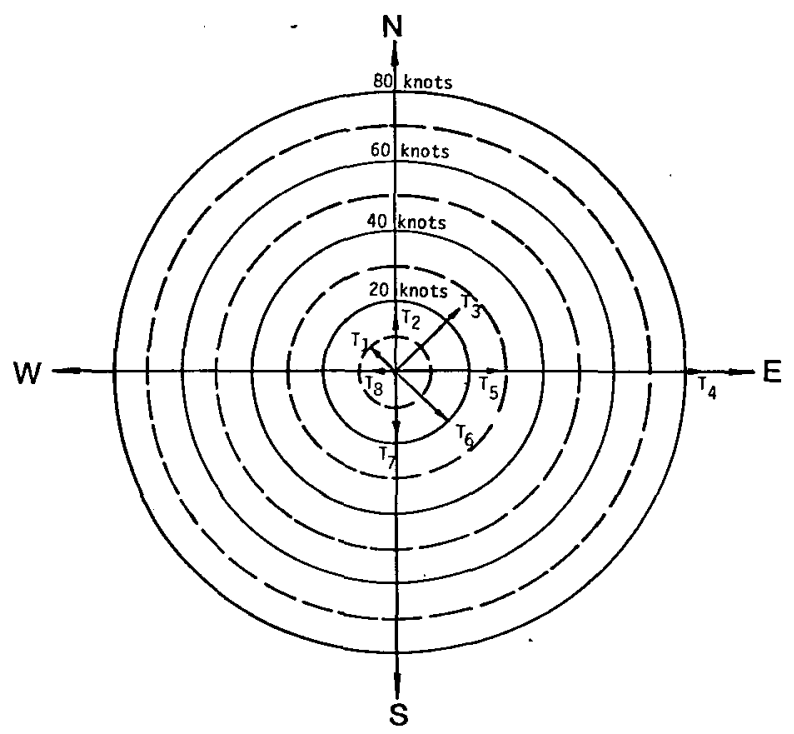

FIG. 6. Change of wind velocity vector with time. $\left(T_{1}=11: 30\right.$ P.M., $T_{2}=11: 50$ P.M., $T_{3}=12: 00$ P.M., $T_{4}=12: 04$ A.M., $T_{5}$ $=12: 09$ A.M., $T_{6}=12: 15$ A.M., $T_{7}=12: 35$ A.M., $T_{8}=1: 10$ A.M.) $T_{1}$ and $T_{8}$ correspond to prestorm and poststorm respectively. Due to the large fluctuations of wind speed and wind direction during the storm, the speed and direction used in this graph are smoothed values rather than instantaneous readings. Since the peak wind lasted only a few seconds, it was not possible to determine the peak wind direction from the graph. The direction of $T_{4}$ was determined from damage investigation rather than the wind direction chart.

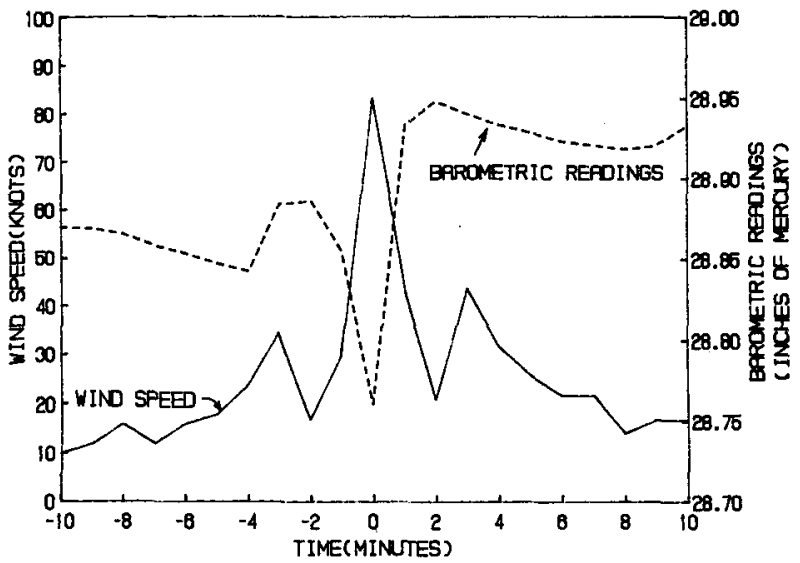

FIG. 7. Comparison of wind speed variation with barometric pressure variation.

It should be mentioned that some compromises had to be made in the foregoing calculations. For instance, the velocity at the building site was assumed to be the same as measured by the anemometer in spite of the fact that the anemometer was located almost $500 \mathrm{~m}$ downwind of the building. Also, the ground level at the building was slightly different from that at the anemometer, and the building height slightly different from the anemometer height. Consequently, the wind speed at the roof height of the building could easily have been $10 \%$ or more different from the velocity used. Despite this inaccuracy, the general conclusion remains valid.

\section{Conclusions}

Wind causes an error in surface pressure measurements, distorting the readings by an amount equal to the internal pressure. This error increases as the square of the wind speed, causing large errors as the wind speed becomes large. The magnitude of this error is of the order of $5 \mathrm{mb}$ when the gust speed is $100 \mathrm{mph}$ ( $45 \mathrm{~m}$ $\mathrm{s}^{-1}$ ), and $20 \mathrm{mb}$ when the gust speed is $180 \mathrm{mph}(80$ $\mathrm{m} \mathrm{s}^{-1}$ ). This means large errors usually exist in surface pressure measurements made in high winds such as hurricanes and tornadoes. The error must be clearly recognized and taken into account in the interpretation of barographs taken in high winds.

A way to correct the error is to subtract the internal pressure from the barograph or microbarograph. This can be done by using Eq. (2) when the areas of the openings on the windward and suction sides are known or can be estimated, and when the average values of the external pressure coefficient are known or can be determined from building codes or published test data. Traces of the variations of wind speed and wind direction with time during the storm must also be known. Such corrections, though only approximate, can reduce the error caused by internal pressure. 


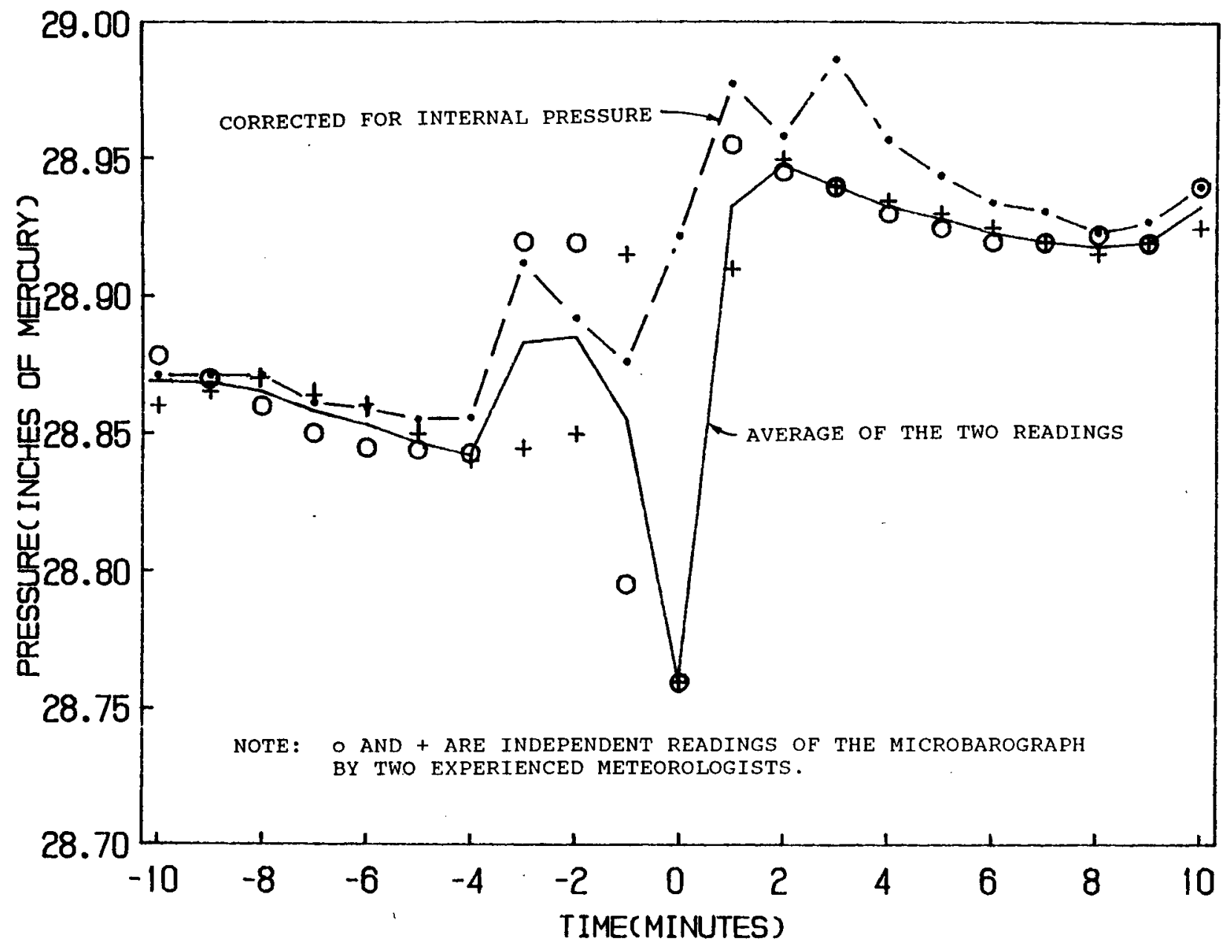

FIG. 8. Correction of storm barograph for internal pressure.

To reduce further or eliminate the effect of internal pressure would require either a more accurate determination of the internal pressure coefficient for individual buildings, or the elimination of internal pressure in measurements. They can be done in at least four ways: 1) conducting field calibration of the building to determine its internal pressure coefficient under different wind directions, 2) running similar tests using building models in a wind tunnel, 3 ) using an omnidirectional static-pressure tube outdoors to gage the true ambient pressure and connecting the indoor pressure sensor to this tube, and 4) connecting the indoor pressure sensor to a ground opening at a suitable location near the building where the pressure is unaffected by the building and by other obstacles. Research is needed in these four areas to determine how accurately the true atmospheric pressure can be determined in wind storms.

Although this paper is focused on wind-induced errors in indoor barometric measurements, outdoor barometric measurements have the same problem. For instance, by placing a pressure sensor outdoors such as in a PAM-2 system (NCAR 1983) used for atmospheric measurements in remote locations, the sensor itself blocks the wind and causes the external pressure on the sensor to vary in the same manner as the variation of external pressure around a building. If the sensor opening happens to face the wind, the dynamic pressure measured by the sensor will be positive. On the other hand, if the sensor opening is on the leeward or on the sides parallel to the wind-as in the case of a downward opening-a negative dynamic pressure will be generated. The reference velocity in this case will be the velocity at the height of the sensor. In addition, if the sensor is placed in a hilly terrain or near other obstacles such as another building, a tree, or a cliff, another dynamic pressure is generated. It can be positive or negative, depending on whether the pressure sensor is located upstream of the obstacle or in the wake or the separation zones of the obstacle. The magnitude of this dynamic pressure is always proportional to the square of the wind speeds. This shows that mea- 
surements of atmospheric pressure, whether indoor or outdoor, are affected by wind. High winds produce intolerable errors in the measurements.

In passing, it may be worthwhile to point out that in general the atmospheric pressure measured with a barometer or microbarometer in wind storm consists of errors generated by 1) a large-scale topographical effect if the pressure sensor is located near or on a hill or mountains, 2) a medium scale building or obstacle effect if the sensor is located inside, on or near a building or near any other obstacles such as trees or a fence, 3) a small-scale effect due to the blockage of wind by the sensor itself if the sensor is exposed to winds, and 4) another small-scale effect owing to the damping mechanism of sensors that vary from one type of sensor to another. The example used in this paper (i.e., the measurements taken at the National Weather Service Building, Columbia Regional Airport) illustrates only one of these effects, namely, the building internal pressure. Other effects are judged to be unimportant in this case.

Acknowledgment. The study was part of a project entitled "Field Study of Building Internal Pressure" sponsored by the National Science Foundation under Grant CEE-8305014. Cooperation by the NWS station personnel at the Columbia Regional Airport in providing the storm data and wind damage information is appreciated. The authors would also like to thank Mr. Bart Hagemeyer, Meteorologist-in-Charge, NWS
Columbia Regional Airport, and Mr. Joseph T. Schaefer, Chief, Scientific Services Division, NWS Center Region, for their valuable comments on the original manuscript.

\section{REFERĖNCES}

American National Standards Institute, 1972: Building Code Requirements for Buildings and Other Structures. ANSI A58.1$1972,60 \mathrm{pp}$.

Brock, F. V., and C. E. Nicolaidis, 1984: Instructor's Handbook on Meteorological Instrumentation. NCAR Tech. Note, NCAR/ $\mathrm{TN}-237+1 \mathrm{~A}$

Fujita, T. T., 1985: The Downburst. SMRP Res. Pap. No. 210, University of Chicago, $122 \mathrm{pp}$.

Liu, H., 1975: Wind Pressure Inside Buildings. Proc. of the Second U.S. Wind Engineering Conference, Fort Collins, III.3.1-III.3.3.

- and P. J. Saathoff, 1981: Building internal pressure-sudden change. J. Struct. Eng., American Society of Civil Engineers, Vol. 107, No. 2, 309-321.

$\longrightarrow$, and - 1982: Internal pressure and building safety. J. Struct. Eng., American Society of Civil Engineers, Vol. 108, No. 10, 2223-2234.

- , and F. Nateghi, 1986: Wind damage to regional airport, Columbia, Missouri, June 17, 1985. Report prepared under National Science Foundation Grant CEE-8305014, University of Missouri-Columbia, $56 \mathrm{pp}$.

-, K. H. Rhee and M. Fartash, 1986: Wind induced pressure inside buildings. Prof. of the Conf. on Advancements in Aerodynamics, Fluid Mechanics and Hydraulics, American Society of Civil Engineers, Minneapolis, 799-805.

NCAR, 1983: Annual Report. National Center for Atmospheric Research (NCAR), Boulder, 60-61.

Simiu, E., and R. H. Scanlan, 1985: Wind effects on structures-an introduction to wind engineering. Wiley and Sons, $589 \mathrm{pp}$. 